\title{
The U.S. Department of Health and Human Services Pain Management Inter-Agency Task Force Emphasizes Patient- Centered Care in its Draft Report
}

\author{
Jianguo Cheng, MD, PhD* \\ President, American Academy of Pain Medicine, Professor and Director of Cleveland Clinic Multidisciplinary Pain Medicine \\ Fellowship Program, Departments of Pain Management and Neurosciences, Cleveland Clinic, USA
}

\begin{abstract}
The U.S. Department of Health and Human Service Pain Management Best Practice Inter-Agency Task Force released its draft report for public comment before finalizing it and reporting to the U.S. Congress. The draft report calls for patient-centered pain care that is interdisciplinary, integrated, and individualized. It identifies and updates clinical guidelines and best practices and makes recommendations to address gaps and inconsistencies in pain management. The recommendations are comprehensive, addressing critical issues about pain education, research, and patient care. Implementation of the recommendations is expected to have a fundamental impact in advancing pain care in the U.S. while mitigating the opioid epidemic that has been national crisis.
\end{abstract}

The U.S. Department of Health and Human Service (HHS) Pain Management Best Practices Inter-Agency Task Force (Task Force) has recently released a draft report [1], calling for individualized, patient-centered pain management to improve the lives of millions of Americans who suffer from acute and chronic pain. As an integral process of the Task Force workflow, members of the public will have 90 days to provide comments on the draft report's proposed comprehensive recommendations.

"Chronic pain affects an estimated 50 million U.S. adults or 20 percent of the adult population. An estimated 19.6 million U.S. adults have experienced high-impact chronic pain, which the CDC defines as pain occurring and interfering with life or work activities most days [2]. This draft report offers a wide range of treatment modalities with a framework to allow for multidisciplinary, individualized patient-centered care", said Vanila M. Singh, M.D., MACM, Task Force chair, and chief medical officer of the HHS Office of the Assistant Secretary for Health. "We encourage members of the public to review the draft report and share their comments with us".

The Task Force, a federal advisory committee, was established by law (the Comprehensive Addiction and
Recovery Act of 2016) [3] and is charged by the U.S. Congress to propose updates to best practices and issue recommendations that address gaps or inconsistencies for managing chronic and acute pain [4]. The objective of these core tasks is to advance pain management in the U.S. and to reduce opioid related overdoses and mortalities. This is a historical milestone in the field of pain medicine and reflects a national effort to address the dual crises of chronic pain and the opioid epidemic in the United States. I am privileged to be one of the Task Force members, who were appointed by the HHS secretary Alex Azar to represent healthcare providers and patients, as well as relevant government agencies. The Task Force members have significant public- and private-sector experience across the disciplines of pain management, substance use disorders, mental health and minority health, and patient advocacy. The Task Force is overseen by the U.S. Department of Health and Human Services, in cooperation with the U.S. Department of Veterans Affairs and the U.S. Department of Defense (DoD).

The draft report contains proposed recommendations in a number of areas of patient-centered pain care. It is particularly noteworthy that, in the draft report, chronic pain is recognized as a category of disease in its own right. It is clearly stated that "pain can be a disease in its own right, particularly when pain becomes chronic and loses its protective function. In this context, pain is often detrimental to the patient's health, functionality, and quality of life. A category of diseases is characterized by chronic debilitating pain (e.g., trigeminal neuralgia, complex regional pain syndrome, postherpetic neuralgia). In such conditions, there is rarely a cure, but appropriate assessment; accurate diagnosis; and patient-centered, multidisciplinary treatment can optimize pain relief, improve function, and enhance quality of life". The draft report specifically identifies the gap that "Pain is generally treated as a symptom of other illness, disease, or injury, not commonly recognized as a separate category of disease. The lack of 
education on pain syndromes and pain mechanisms limits the ability to recognize chronic pain as a category of disease". It recommends to "recognize chronic pain as a category of disease when the pain persists for more than the expected recovery time (3-6 months) despite appropriate treatment of the original inciting injury or disease". Adopting this concept in the medical community will have a profound impact on pain education, patient care, and research.

The draft report updates clinical best practices/ guidelines; recommends multimodal and interdisciplinary approaches to acute and chronic pain management; addresses barriers to access to pain care, as well as stigma around chronic pain and substance use disorder; and emphasizes education of healthcare providers, patients, and the public. It also addresses special populations, including older adults, women, ethnic and racial minorities, military members and veterans, and special conditions, such as pregnancy, chronic relapsing pain and sickle cell disease. In addition, the Task Force calls for acquiring better evidence to guide clinical decision-making through funding scientific and clinical research of pain and substance use disorder. Specifically, it recommends to "Increase federal (and state) funding through the National Institutes of Health (NIH), the DoD, and other agencies to support and accelerate basic science, translational, and clinical research of pain. Allocate funding to develop innovative therapies and build research capabilities for better clinical outcomes tracking and evidence gathering". And finally, it conducted a congressionally mandated review of the Centers for Disease Control and Prevention (CDC) Guideline for Prescribing Opioids for Chronic Pain [5].

The Task Force will review the comments submitted by the public, make further refinement, and submit the finalized report to the U.S. Congress in May, 2019. Implementation of the recommendations is expected to fundamentally advance patient care, education, and research and improve quality of life for patients living in pain.

Although the Task Force is charged to specifically address pain management in the United States, many of its recommendations, such as multimodal and multidisciplinary approach to patient-centered pain care, evidence-informed clinical guidelines and decision-making, and treating chronic pain as a category of disease by utilizing chronic disease management models, may be applicable to other parts of the world. Recommendations on pain education and research may also be modeled by other countries and regions. Therefore, the report may have far-reaching impact on pain care much beyond the United States.

\section{References}

1. U.S. Department of Health and Human Services: Draft Report on Pain Management Best Practices: Updates, Gaps, Inconsistencies, and Recommendations. Washington D.C., December 28, 2018. https://www.hhs.gov/ash/advisorycommittees/pain/reports/2018-12-draft-report-on-updatesgaps-inconsistencies-recommendations/index.html

2. Dahlhamer J, Lucas J, Zelaya C, Nahin R, Mackey S, DeBar L, Kerns R, Von Korff M, Porter L, Helmick C: Prevalence of Chronic Pain and High-Impact Chronic Pain Among Adults - United States, 2016. MMWR Morb Mortal Wkly Rep 2018; 67: 1001-1006.

3. U.S. Congress, S.524 - Comprehensive Addiction and Recovery Act of 2016. 114th Congress (2015-2016). Washington D.C. , 2016. https://www.congress.gov/ bill/114th-congress/senate-bill/524/text

4. U.S. Department of Health and Human Services (HHS) Pain Management Inter-Agency Task Force. . Washington D.C. , May 21, 2018. https://www.hhs.gov/ash/advisorycommittees/pain/index.html

5. Dowell D, Haegerich TM, Chou R: CDC Guideline for Prescribing Opioids for Chronic Pain--United States, 2016. JAMA 2016; 315: 1624-45.

Corresponding Author: Jianguo Cheng, MD, PhD, Professor and Director of Cleveland Clinic Multidisciplinary Pain Medicine Fellowship Program, Departments of Pain Management and Neurosciences, Cleveland Clinic, 9500 Euclid Avenue, Cleveland, Ohio, 44195, USA, Tel: (216)444-0237, Fax: (216)-444-9890,E-mail: chengj@ccf.org

Editor: Renyu Liu, MD, PhD, Associate Professor, Department of Anesthesiology and Critical Care, Perelman School of Medicine at the University of Pennsylvania, 336 John Morgan building, 3620 Hamilton Walk, Philadelphia, PA 19104, Phone: 2157461485, Email: liur@uphs.upenn.edu

\section{Additional publication details}

Journal short name: Transl Perioper \& Pain Med

Received Date: January 09, 2019

Accepted Date: January 09, 2019

Published Date: January 11, 2019

Citation: Cheng J. The U.S. Department of Health and Human Services Pain Management Inter-Agency Task Force Emphasizes Patient-Centered Care in its Draft Report. Transl Perioper \& Pain Med 2019; 6 (1):1-2

Copyright: (C) 2019 Cheng J. This is an open-access article distributed under the terms of the Creative Commons Attribution License, which permits unrestricted use, distribution, and reproduction in any medium, provided the original author and source are credited. 